\title{
PTU-088 스 WHAT ROLE DOES SURGERY PLAY IN THE MODERN DAY MANAGEMENT OF NON-VARICEAL UPPER GASTROINTESTINAL BLEEDING?
}

doi:10.1136/gut.2011.239301.216

V Jairath, ${ }^{1 *}$ R Logan, ${ }^{2}$ S Hearnshaw, ${ }^{3}$ B Kahan, ${ }^{4}$ S Travis, ${ }^{5}$ M Murphy, ${ }_{1}$ K Palmer ${ }^{6}{ }^{1} \mathrm{NHS}$ Blood and Transplant, Oxford, UK; ${ }^{2}$ Division of Epidemiology and Public Health, Nottingham, UK; ${ }^{3}$ Royal Victoria Infirmary, Newcastle, UK; ${ }^{4}$ MRC Clinical Trials Unit, London, UK; ${ }^{5}$ John Radcliffe Hospital, Oxford, UK; ${ }^{6}$ Western General Infirmary, Edinburgh, UK

Introduction Combinations of endoscopic, pharmacological and radiological intervention appears to have reduced the need for surgery in non-variceal upper gastrointestinal bleeding (NVUGIB), for what was once a condition primarily managed by surgeons. The place of surgery in today's management of NVUGIB remains poorly characterised.

Methods We examined the clinical characteristics, sequence of intervention and outcomes of NVUGIB in a nationwide study, by analysing patients coming to surgery in the 2007 national audit of Acute Upper Gastrointestinal Bleeding ${ }^{1}$.

Results The study recruited 6,750 patients. Only $1.9 \%$ (127/6750) underwent surgery. The mean age was 69.4 (SD 15) years, $60 \%(75 / 127)$ male, with median of 1 co-morbid illnesses. Indications for surgery were uncontrolled bleeding/high risk stigmata of haemorrhage in $82 \%(104 / 127)$, peritonitis/perforation in $12 \%(15 / 127)$, malignancy in $4 \%$ $(5 / 127)$, and other indications in $9 \%(12 / 127)$. Surgical procedures were oversew or under-run of an ulcer in $65 \%$ (83/127), 
partial gastrectomy in $9 \%(12 / 127)$, excision of an ulcer with vagotomy/pyloroplasty (2\%) and other procedure in $20 \%$. Surgery was performed outside of normal working hours in $54 \%(69 / 127)$, lead by a consultant surgeon in $71 \%(90 / 127)$ with a consultant anaesthetist in $64 \%(81 / 127)$. A median of 1 endoscopy was performed prior to surgery and $5 \%(6 / 127)$ had also undergone mesenteric angiography, with apparently successful embolisation in 33\% (2/6) of cases. Mortality following surgery was $30 \%(38 / 127)$. Post-operative complications occurred in $65 \%$ (82/127). Compared to patients managed non-surgically, patients requiring surgery were older (mean $69.4 y$ rs vs. 64.3 yrs, $p<0.0001$ ), more likely to have been shocked $(66 \%$ vs. $36 \%$ p $<0.0001)$, transfused a greater number of red cells (median 9 units vs. 4 units, $p<0.0001$ ) and have a higher complete Rockall score (median 6 vs. 4, p<0.0001). AUROC analysis showed that the complete Rockall score usefully predicted the need for surgery (AUC 0.74, 95\% CI 0.7-0.78), but the clinical Rockall score did not (AUC 0.613, 95\% CI 0.56-0.67).

Conclusion Modern day management of NVUGIB rarely requires surgical intervention. Given the high mortality and complication rates of patients following surgery, its role and timeliness needs re-evaluation in the hope of improving outcomes following AUGIB.

Competing interests None.

\section{REFERENCE}

1. UK Comparative Audit of Upper Gastrointestinal Bleeding and the Use of Blood. British Society of Gastroenterology. 2007. http://www.bsg.org.uk/pdf_word_ docs/blood_audit_report_07.pdf 